\begin{tabular}{|l|l|l|l|l|l|}
\hline $\begin{array}{l}\text { Nereis. Revista Iberoamericana } \\
\text { Interdisciplinar de Métodos, } \\
\text { Modelización y Simulación }\end{array}$ & 12 & $71-90$ & $\begin{array}{c}\text { Universidad Católica de } \\
\text { Valencia San Vicente Mártir }\end{array}$ & $\begin{array}{c}\text { Valencia } \\
\text { (España) }\end{array}$ & \begin{tabular}{l} 
ISSN 1888-8550 \\
\hline
\end{tabular}
\end{tabular}

\title{
Especies vegetales como antioxidantes de alimentos
}

\author{
Plant species as food antioxidants
}

Fecha de recepción y aceptación: 24 de febrero de 2020, 22 de mayo de 2020

DOI: $10.46583 /$ nereis_2020.12.577

\author{
Juan José Serra Bisbal ${ }^{1}$, Joana Melero Lloret ${ }^{2}$, Gemma Martínez Lozano ${ }^{3}$ y Carmen Fagoaga Garcia ${ }^{3 *}$ \\ ${ }^{1}$ Escuela de Doctorado. Universidad Católica de Valencia San Vicente Mártir. \\ ${ }^{2}$ Servicio de Cardiología, Sección de Hemodinámica. Hospital General Universitario de Castellón. \\ ${ }^{3}$ Departamento de Ciencias Experimentales y Matemáticas. Facultad de Veterinaria y Ciencias Experimentales. Universidad Católica \\ de Valencia San Vicente Mártir. \\ * Correspondencia: Universidad Católica de Valencia San Vicente Mártir. Facultad de Veterinaria y Ciencias Experimentales. Calle \\ Guillem de Castro 94. 46001, Valencia. España.E-mail: carmen.fagoaga@ucv.es
}

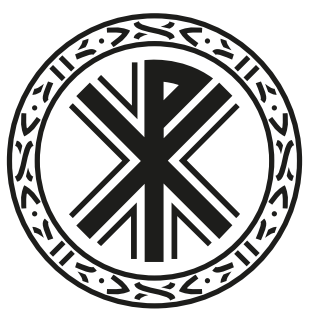

\section{RESUMEN}

La oxidación lipídica es la principal reacción deteriorativa de los alimentos, tanto en el procesado como en su almacenamiento. Ambas circunstancias limitan la vida de la mayoría de los alimentos, lo que causa olor y sabor a rancidez en ellos, un proceso que se conoce como rancidez oxidativa. Además, la oxidación lipídica puede dañar membranas biológicas, enzimas y proteínas, y provocar la aparición de compuestos secundarios potencialmente tóxicos. Para controlar estos procesos oxidativos, la adición de antioxidantes es una estrategia común contra las reacciones oxidativas en el procesado o almacenamiento de los alimentos. Los antioxidantes comúnmente utilizados han empezado a preocupar en la sociedad actual acerca de los efectos nocivos que puedan tener en la salud humana.

Recientemente está emergiendo una industria de antioxidantes naturales derivados de especies vegetales que pueden reemplazar a los antioxidantes sintéticos. El enriquecimiento de alimentos procesados con extractos de vegetales no solo resuelve el problema de la oxidación del alimento sino que también puede resultar en una mejora de la salud del consumidor. Estos compuestos naturales son mayoritariamente polifenoles (ácidos fenólicos, flavonoides, antocianinas, ligninas), carotenoides (xantofilas y carotenos), tocoferoles, tocotrienoles y algunos aminoácidos y péptidos. Se encuentran ampliamente distribuidos en las diferentes especies de cereales, aromáticas, frutales, cultivos hortícolas y semillas oleaginosas. Los antioxidantes naturales presentes en especies vegetales aromáticas como el romero (Rosmarinus officinalis L.) y la salvia (Salvia officinalis L.) ya se están comercializando como conservantes alimentarios naturales y seguros, aplicándose en alimentos ricos en grasas como los aceites vegetales.

PALABRAS CLAVE: oxidación lipídica, antioxidantes naturales, especie vegetal, actividad antioxidante. 


\begin{abstract}
Lipid oxidation is the main deterioration reaction during the processing of food, as well as in its storage. Both circumstances limit the shelf-life of most foods, causing musty smell and taste in them, a process which is known as oxidative rancidity. In addition, lipid oxidation can damage biological membranes, enzymes and proteins, resulting in the appearance of potentially toxic secondary compounds. To control these oxidative processes, the addition of antioxidants is a common strategy against oxidative reactions in the processing or storage of food. The antioxidants that are commonly used have begun to concern today's society that they may have harmful effects on human health.

Recently, an industry of natural antioxidants derived from plant species and that can replace synthetic antioxidants is thus emerging. Not only does the enrichment of processed foods with vegetable extracts solve the problem of oxidation of food, but it can also result in an improvement of the consumer's health. These natural compounds are mainly polyphenols (phenolic acids, flavonoids, anthocyanins, lignins), carotenoids (xanthophylls and carotenes), tocopherols, tocotrienols and some amino acids and peptides. They are widely distributed in species of cereals, aromatics, fruit trees, horticultural crops and oilseeds.

Natural antioxidants present in aromatic plant species such as rosemary (Rosmarinus officinalis L.) and sage (Salvia officinalis L.) are already being marketed as natural and safe food preservatives, being applied to foods which are rich in fats such as vegetable oils.
\end{abstract}

KEYWORDS: lipid oxidation, natural antioxidants, plant species, antioxidant activity.

\title{
INTRODUCCIÓN
}

Los lípidos presentes en los alimentos son principalmente triacilglicéridos, fosfolípidos y esteroles que se encuentran de forma natural en los alimentos que se consumen directamente o bien se agregan como ingredientes funcionales en muchos alimentos procesados. La característica común de estas moléculas es que son solubles en solventes no polares pero no en agua. Los triacilglicéridos (un subgrupo de lípidos), son también conocidos como grasas y están constituidos por tres ácidos grasos y una molécula de glicerol.

Los ácidos grasos se pueden clasificar según su longitud de cadena de carbono: ácidos grasos de cadena corta (contienen menos de 6 átomos de carbono), ácidos grasos de cadena media (8-12 átomos de carbono), ácidos grasos de cadena larga (14-18 átomos de carbono) y ácidos grasos de cadena muy larga (igual o más de 20 átomos de carbono). Por otra parte, estos también pueden clasificarse por el número de dobles enlaces que contienen en su cadena hidrocarbonada: ácidos grasos saturados (SFA), si no hay un doble enlace presente; ácidos grasos monoinsaturados (MUFA), si solo está presente un doble enlace; y ácidos grasos poliinsaturados (PUFA), si están presentes dos o más dobles enlaces en la mencionada cadena (figura 1). 


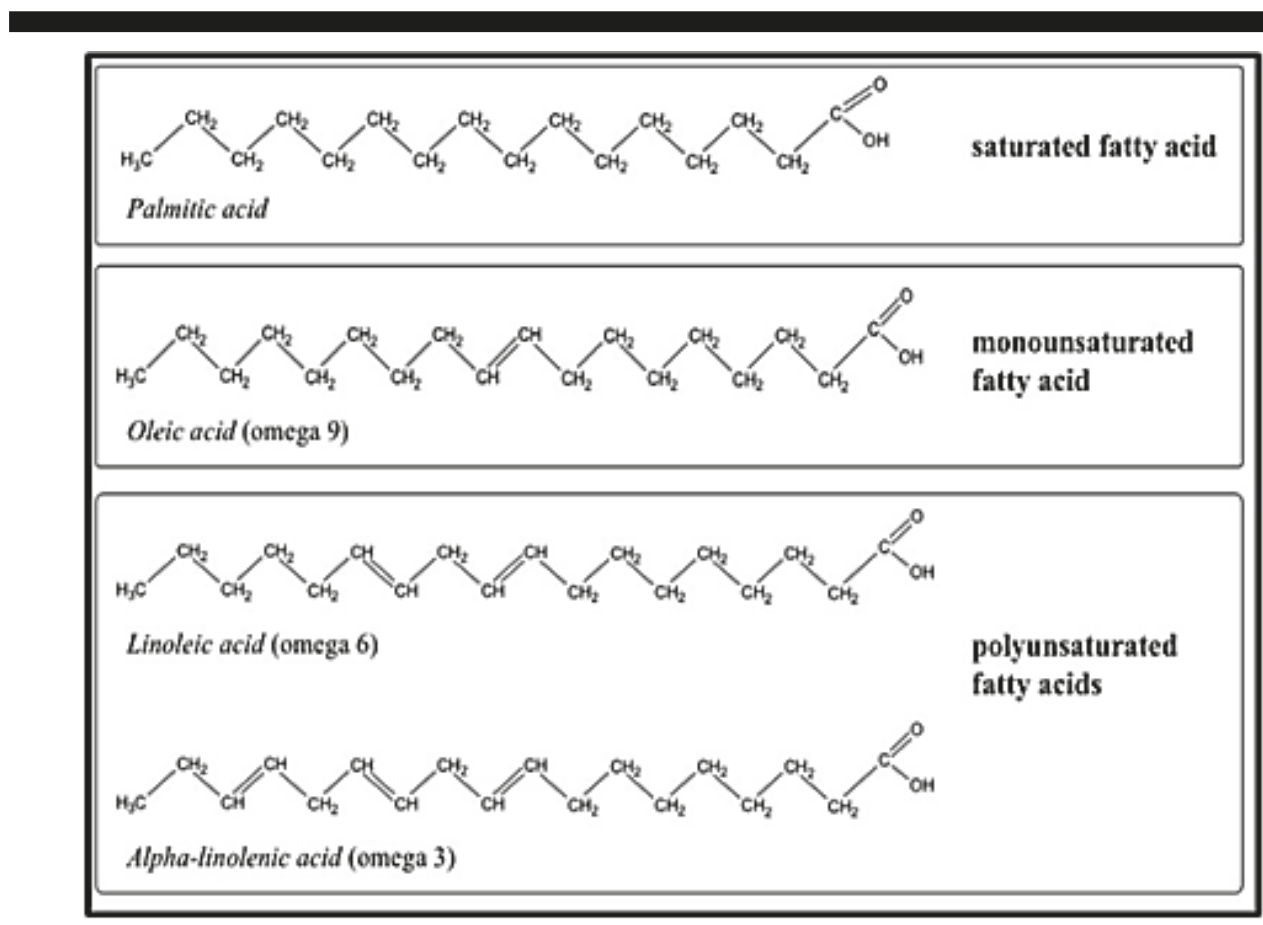

Fig. 1. Ejemplos de ácidos grasos saturados, monoinsaturados y poliinsaturados [1].

Las especies reactivas del oxígeno (ROS=Reactive Oxygen Species) son moléculas que exhiben mayor reactividad química que el oxígeno y son conocidas por formarse en todos los organismos aeróbicos y desempeñar una gran variedad de funciones. Un radical libre se puede definir como cualquier especie molecular independiente que contiene uno o más electrones desapareados en un orbital atómico. Estos electrones desapareados les confieren unas características determinadas, entre ellas, una capacidad altamente reactiva e inestabilidad energética. También pueden donar o aceptar electrones actuando en calidad de oxidantes o reductores [2].

La oxidación de los lípidos se ha identificado como el principal proceso de deterioro de los alimentos ricos en grasas que afecta a la calidad de los mismos, al valor nutricional, al color, al desarrollo de sabores desagradables e incluso a la propia seguridad y aceptación de los alimentos por parte de los consumidores. Además, algunos de los compuestos formados durante la oxidación pueden tener consecuencias indeseables para la salud.

La oxidación lipídica ocurre principalmente como un resultado del deterioro oxidativo de los ácidos grasos poliinsaturados (PUFAs) [3]. Las reacciones de oxidación consisten en autooxidaciones y oxidaciones enzimáticas y fotooxidaciones, siendo la auto-oxidación la más común cuando se trata de almacenamiento y conservación de alimentos [4] (figura 2). 


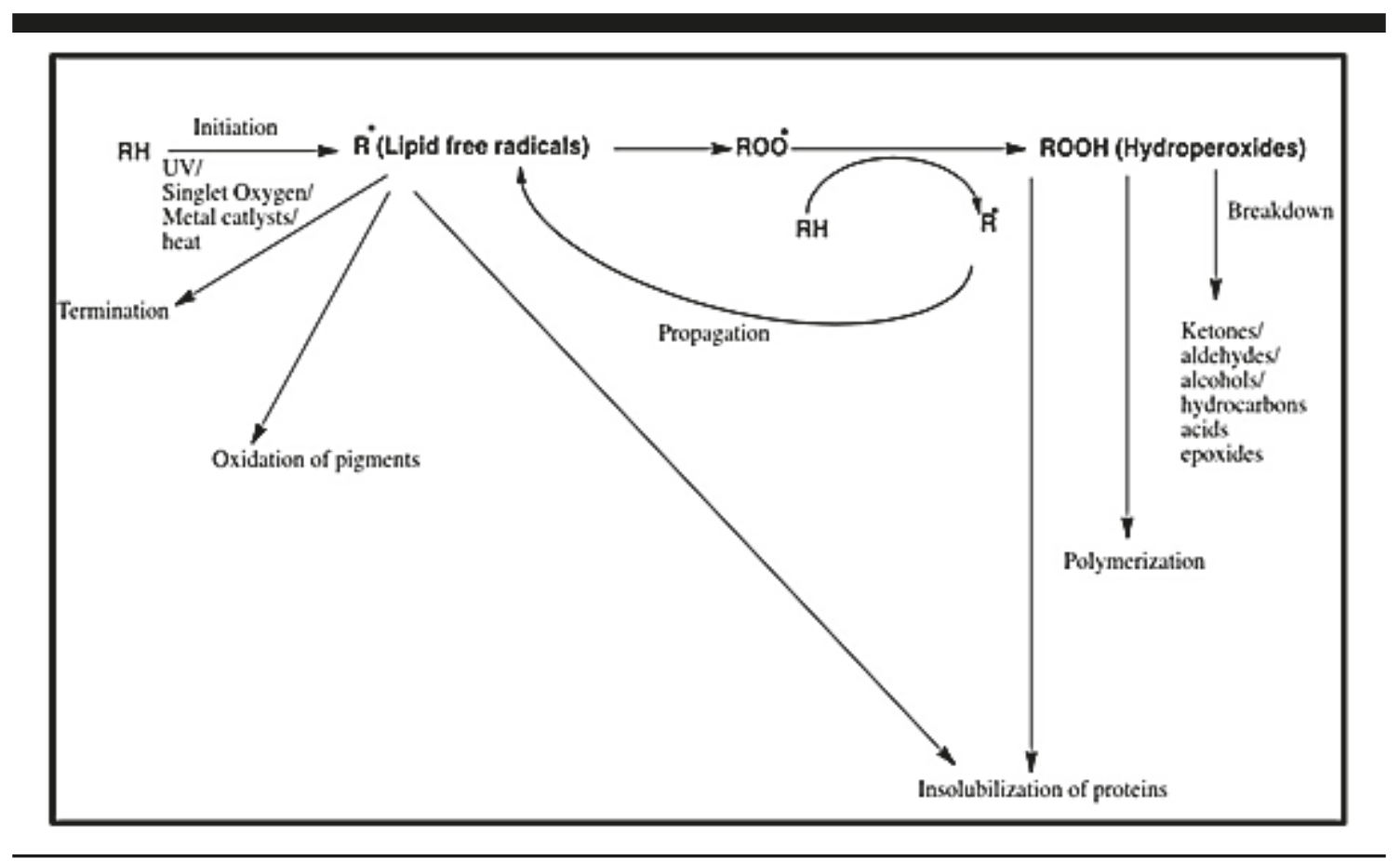

Fig. 2. Representación esquemática de la autooxidación lipídica [5].

La oxidación enzimática de los lípidos en los alimentos grasos es causada principalmente por enzimas hidrolasas de ésteres carboxílicos. Se trata de metaloproteínas con $\mathrm{Fe}^{2+}$ en su centro activo. A diferencia de la autooxidación: las hidrolasas tienen especificidad por el sustrato, el pH óptimo de la reacción es muy estricto, la temperatura ha de ser óptima, las enzimas presentan sensibilidad al calor y se requiere de una energía de activación muy baja, en torno a los $17 \mathrm{~kJ} / \mathrm{mol}$. La fotooxidación ocurre cuando un alimento se expone a la luz en presencia de sensibilizados y oxígeno atmosférico [6]. La Luz puede desencadenar la oxidación de los lípidos de dos maneras diferentes, ambas mediadas por pequeñas cantidades de compuestos llamados fotosensibilizadores.

Entre los factores que tienen una influencia notable en la oxidación lipídica, destacan la composición lipídica, los componentes minoritarios y los factores ambientales tales como la temperatura, la luz, la humedad y la presencia de oxígeno [4].

Los componentes minoritarios presentes en un alimento interactúan en un equilibrio complejo entre factores antioxidantes y prooxidantes. Los antioxidantes inhiben la oxidación en los alimentos inactivando los radicales libres, aplacando el oxígeno y los fotosintetizadores y quelando iones metálicos prooxidantes [6]. No obstante, la actividad antioxidante depende de la concentración y la localización del antioxidante en el propio alimento. En algunos casos, el mismo antioxidante que inhibe la oxidación en un alimento puede producir un efecto prooxidante en otro [7]. Algunos metales de transición como el hierro $\left(\mathrm{Fe}^{2+} / \mathrm{Fe}^{3+}\right)$ y el cobre $\left(\mathrm{Cu}^{+} / \mathrm{Cu}^{2+}\right)$, son componentes minoritarios de alimentos que pueden servir tanto para iniciar como para acelerar una reacción de oxidación lipídica [8] (figura 3). 


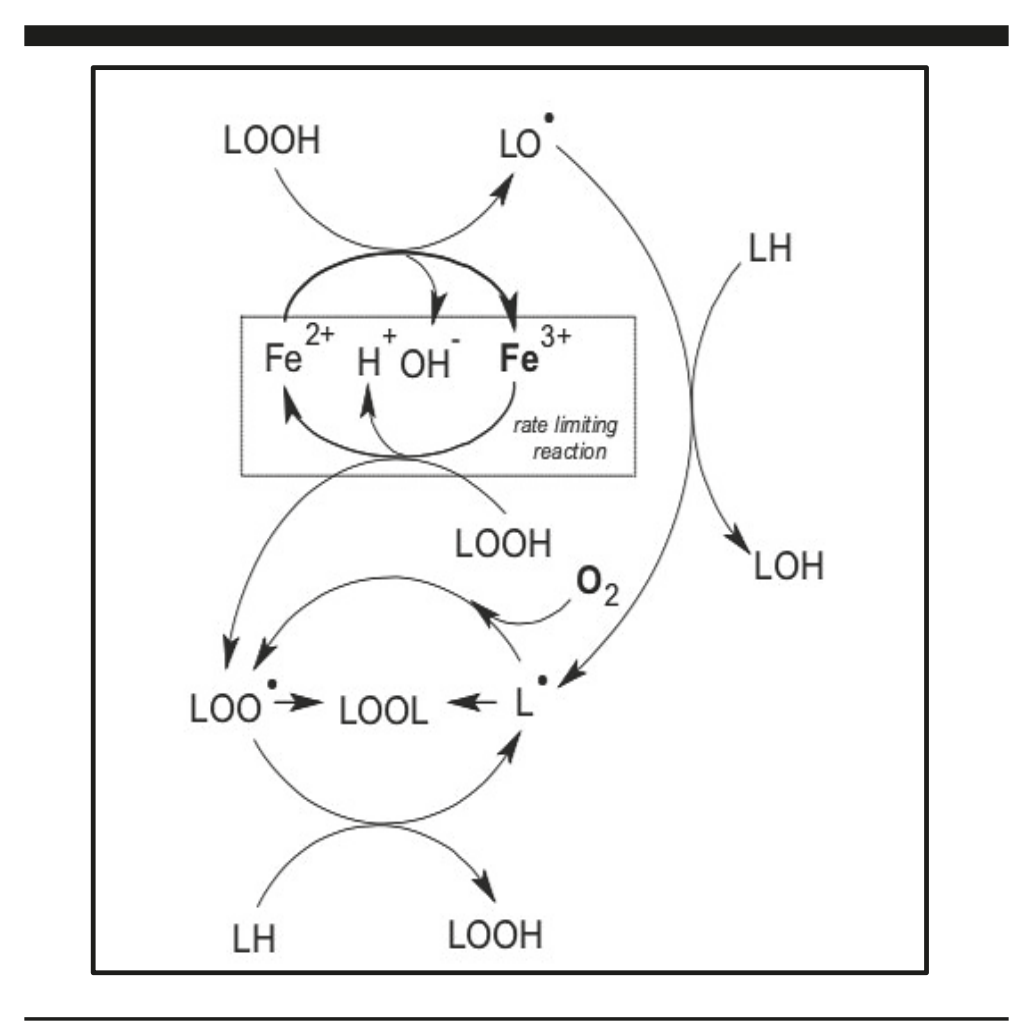

Fig. 3. Mecanismo de oxidación lipídica mediada por hierro [8].

La estabilidad oxidativa es un parámetro importante para evaluar la calidad de los aceites y grasas; se refiere a la capacidad de resistir la rancidez oxidativa (o deterioro) durante los periodos de procesamiento y almacenamiento.

La composición de los ácidos grasos, la presencia de metales como el hierro, los antioxidantes o los fotosensibilizadores (clorofila) son algunos de los factores que pueden influir en la estabilidad oxidativa de los alimentos.

\section{ANTIOXIDANTES EN LA OXIDACIÓN LIPÍDICA}

Un antioxidante es una molécula lo suficientemente estable como para donar un electrón a un radical libre y neutralizarlo. Estos retardan o inhiben el daño celular principalmente por su propiedad de recoger o eliminar los radicales libres, interfiriendo en las primeras fases de la oxidación. Es posible utilizar antioxidantes para retardar la oxidación de lípidos en alimentos [9].

Los tres mecanismos fundamentales de actividad antioxidante se basan en la transferencia de un átomo de hidrógeno, en la transferencia de un único electrón o en la actividad quelante característica de los metales. Los polifenoles inactivan los radicales libres de acuerdo con la transferencia de átomos de hidrógeno (HAT) y los mecanismos de transferencia de un solo electrón (SET) (figura 4). 
En el mecanismo 1 (Hydrogen Atom Transfer), el antioxidante (ArOH) reacciona con el radical libre $(\mathrm{R})$ transfiriendo un átomo de hidrógeno, a través de la ruptura homolítica del enlace O-H. Los productos de la reacción son especies de $\mathrm{RH}$ inofensivas y el radical ArO· oxidado. Incluso si la reacción conduce a la formación de otro radical, es menos reactiva con respecto a $\mathrm{R} \cdot$ porque se estabiliza.

En el mecanismo 2 (Single Electron Transfer), lo que sucede es la transferencia del electrón de la ruptura homolítica (HOMO). En las estructuras aromáticas $\mathrm{ArO} \cdot \mathrm{y} \mathrm{ArOH} \cdot$ que tienen el electrón impar, originado por las reacciones con el radical libre, el electrón tiene la posibilidad de extenderse por toda la molécula, resultando en una estabilización radical.

Por último, en el mecanismo 3 (Transition Metals Chelation) los iones de metales de transición pueden ser quelados por polifenoles, resultando en compuestos complejos estables. Estos atrapan los metales y evitan que participen en las reacciones que generan los radicales libres. Metales de transición como el cobre, el manganeso y el cobalto son capaces de catalizar esta reacción, bajo ciertas condiciones cuando estos iones metálicos no están unidos a proteínas o quelantes (figura 4).

1. Hydrogen Atom Transfer (HAT)

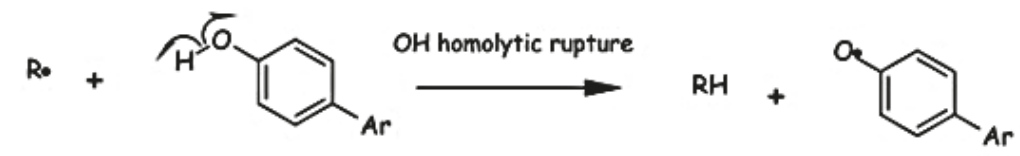

2. Sigle Electron Transfer (SET)

R. +<smiles>Oc1ccc(Br)cc1</smiles>

electron abstraction from the HOMO

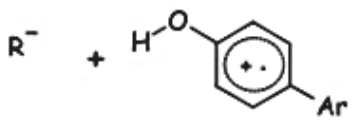

3. Transition Metals Chelation (TMC)<smiles>N#[W]c1ccc(-c2oc3cc(O)cc(O)c3c(=O)c2O)cc1O</smiles>

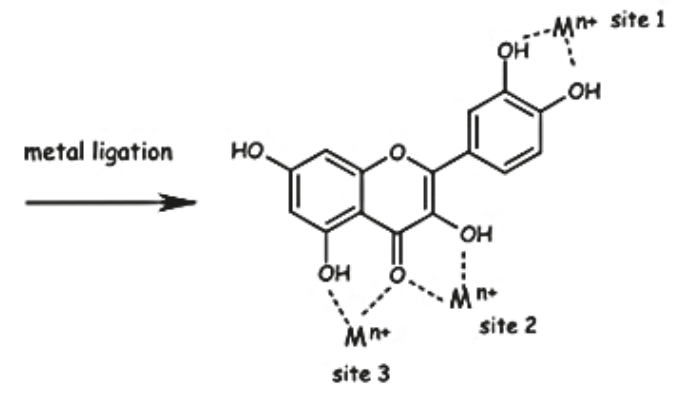

Fig. 4. Mecanismos de actividad antioxidante [11] (HOMO: homolytic rupture). 


\section{ANTIOXIDANTES EMPLEADOS EN LA CONSERVACIÓN DE ALIMENTOS}

Desde hace cientos de años los antioxidantes se han usado en la conservación de alimentos con el objetivo de prolongar el tiempo de almacenamiento. También se utilizan como conservantes del color, del sabor, y del aroma, así como para mantener su valor nutricional y prolongar la vida del producto. Las especies vegetales usadas como antioxidantes naturales se presentan en diferentes formas: el material vegetal, ya sea completo o molido, como extracto, como una oleorresina o como un compuesto bioactivo aislado.

\section{Antioxidantes sintéticos}

Los antioxidantes más comunes que se utilizan en los alimentos son principalmente fenólicos, como el hidroxianisol butilado (BHA), el hidroxitolueno butilado (BHT) y la butilhidroquinona terciaria (TBHQ). También algunos gálicos como el propilo de galato (PG), el galato de octilo (OG) y el dodecil galato (DG).

El mecanismo de acción de estos antioxidantes para evitar el proceso oxidativo se basa en atrapar los radicales peroxilos. El fenol dona un átomo de hidrógeno y termina la propagación de otras reacciones [12].

Estos antioxidantes sintéticos han sido sometidos a diferentes test y ensayos para comprobar su seguridad. Sin embargo, a pesar de que se han estado utilizando durante estos últimos años, todavía existen dudas acerca de su seguridad para el uso alimentario. Se requieren estudios por sus posibles efectos mutagénicos, teratogénicos y carcinogénicos [13]. Se ha comprobado que los antioxidantes sintéticos sí pueden tener propiedades tóxicas siempre a altas concentraciones. El BHA y el BHT se han relacionado con daño hepático y carcinógeno en animales de laboratorio. También pueden inducir daño en el DNA o tener la capacidad de ser iniciadores de un cáncer [13]. Parece lógico pensar que si hay alguna posibilidad de que sean nocivos, tratemos de reemplazarlos por compuestos que sean más compatibles con la naturaleza del ser humano [4].

El uso de estos antioxidantes está estrictamente regulado y difiere según los diferentes países. El BHA y el BHT se han estado utilizando desde hace 70 años y el TBHQ se permitió en Europa a partir del año 2004, pero en algunos países, como Japón, todavía no se ha aceptado. El BHA es el antioxidante sintético más utilizado de todos, debido a su capacidad de soportar altas temperaturas. En países como China, Brasil, Nueva Zelanda y Filipinas el uso del TBHQ está permitido en alimentos en cantidades de hasta $200 \mathrm{mg} / \mathrm{kg}$ [4].

\section{Antioxidantes naturales de origen vegetal}

Los metabolitos secundarios en plantas, constituyen un enorme reservorio de biodiversidad química. Estos productos secundarios vegetales pueden clasificarse en varios grupos según su estructura química. En está revisión nos centraremos en explicar detalladamente aquellos que están implicados en funciones antioxidantes. 
Tocofenoles y tocotrienoles: Ambos son derivados del 6-cromanol, diferenciándose en el número y la posición de los sustituyentes de metil en el anillo fenólico y en las cadenas del $\mathrm{C}^{2}$. Las propiedades de eliminación de radicales libres propias de estos compuestos radica en la facilidad que poseen para donar el hidrógeno fenólico o su energía de disociación de enlace [9]. El $\alpha$-tocoferol (con dos sustituyentes orto metilo) es un fuerte donador de hidrógeno, más potente que los tocoferoles $\beta$ o $\gamma$ (con un solo sustituyente orto metilo) y a su vez más potentes que el $\delta$-tocoferol, el cual no posee un sustituyente orto metilo [14].

Las cadenas laterales saturadas de los tocoferoles e insaturadas de los tocotrienoles son las responsables de contribuir a su acción antioxidante y eliminadora de radicales libres (figura 5). Ambos compuestos, los tocoferoles y tocotrienoles, tienen efectos similares en la protección de los lípidos contra la oxidación [15].

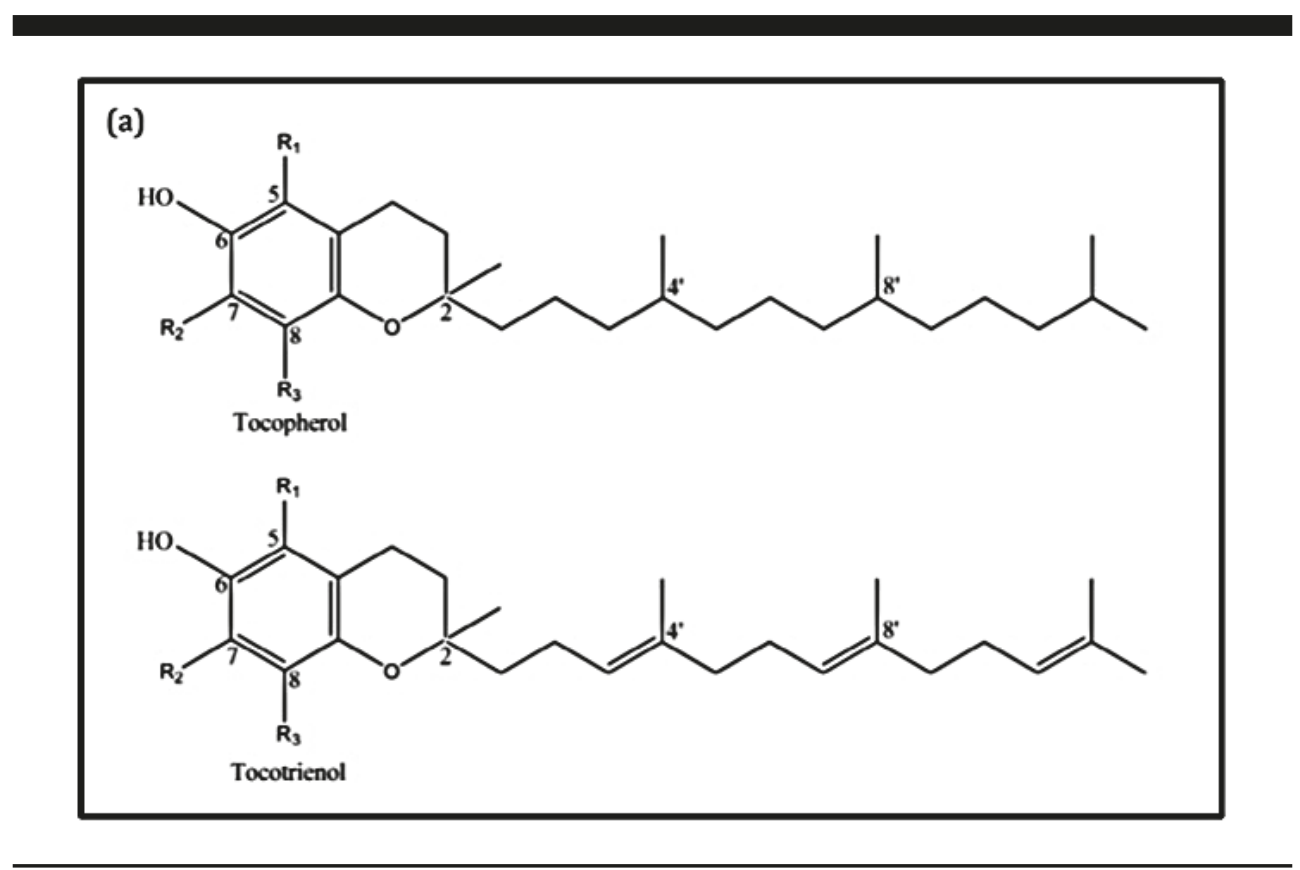

Fig. 5. Estructuras químicas de tocoferoles y tocotrienoles [5].

En algunos estudios [16] se compararon las potencias de los dos tocoferoles $\alpha$-tocoferol y $\gamma$-tocoferol, concluyendo que $\gamma$-tocoferol era siempre más potente que $\alpha$-tocoferol a concentraciones altas $(>50 \mathrm{ppm})$. Mediante la técnica de cromatografía líquida de alta presión (HPLC $=$ High Performance Liquid Chromatography) se demostró que tanto $\alpha$-tocoferol como $\gamma$-tocoferol son donadores de hidrógeno efectivos que son capaces de inhibir la isomerización trans de hidroperóxidos y su descomposición en compuestos hidroxi y cetodianas $[17,6,9,18]$.

Los tocoferoles cuando se usan a altas temperaturas se descomponen rápidamente y pierden su función protectora frente a la oxidación. 
Fenoles: son compuestos que contienen anillos aromáticos (fenil) con al menos un grupo hidroxilo añadido (figura 6). El grupo hidroxilo del fenol es ácido, lo que facilita la estabilización de un oxígeno desprotonado sustituyente.

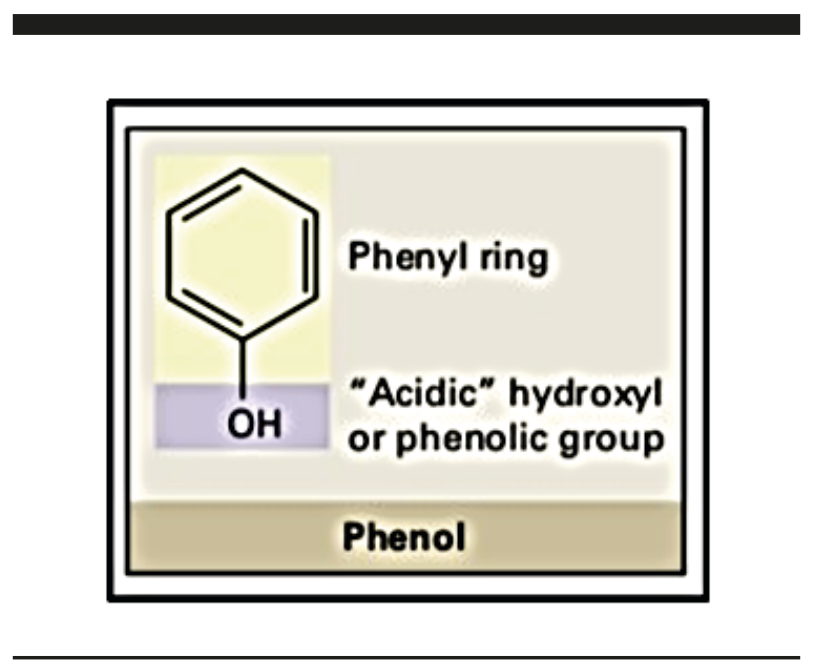

Fig. 6. Estructura de un fenol.

Biológicamente los fenoles realizan un sinfín de funciones, desde ser componentes estructurales de las paredes celulares, actuar como agentes colorantes de frutos y flores, aromatizar órganos vegetales hasta actuar como antioxidantes protectores de la madera, corcho y semillas.

Mayoritariamente estos compuestos provienen de esqueletos de fenilpropanoides y fenilpropanoides-acetatos. Las rutas bioquímicas de estos dos compuestos producen compuestos que en el pasado contribuyeron a la adaptación de las plantas desde el medio marino hasta el medio terrestre. En concreto la ruta del fenilpropanoide-acetato conlleva la producción de una gran diversidad de compuestos y culmina con la formación de compuestos con una estructura $\mathrm{C}_{6}-\mathrm{C}_{3}-\mathrm{C}_{6}$, que incluye a los flavonoides y a los diarilheptanoides.

Flavonoides: están constituidos por una estructura básica de tres anillos aromáticos, que es modificada para producir varias subclases, tales como las antocianinas (pigmentos), proantocianidinas (taninos condensados), isoflavonoides, flavonas y flavonoles (agentes antiinflamatorios en animales). Estos compuestos fueron los primeros fenoles complejos producidos por plantas. Son responsables de la gran diversidad de compuestos formados a partir de L-fenilalanina (L-Phe) en el reino vegetal (figura 7). 


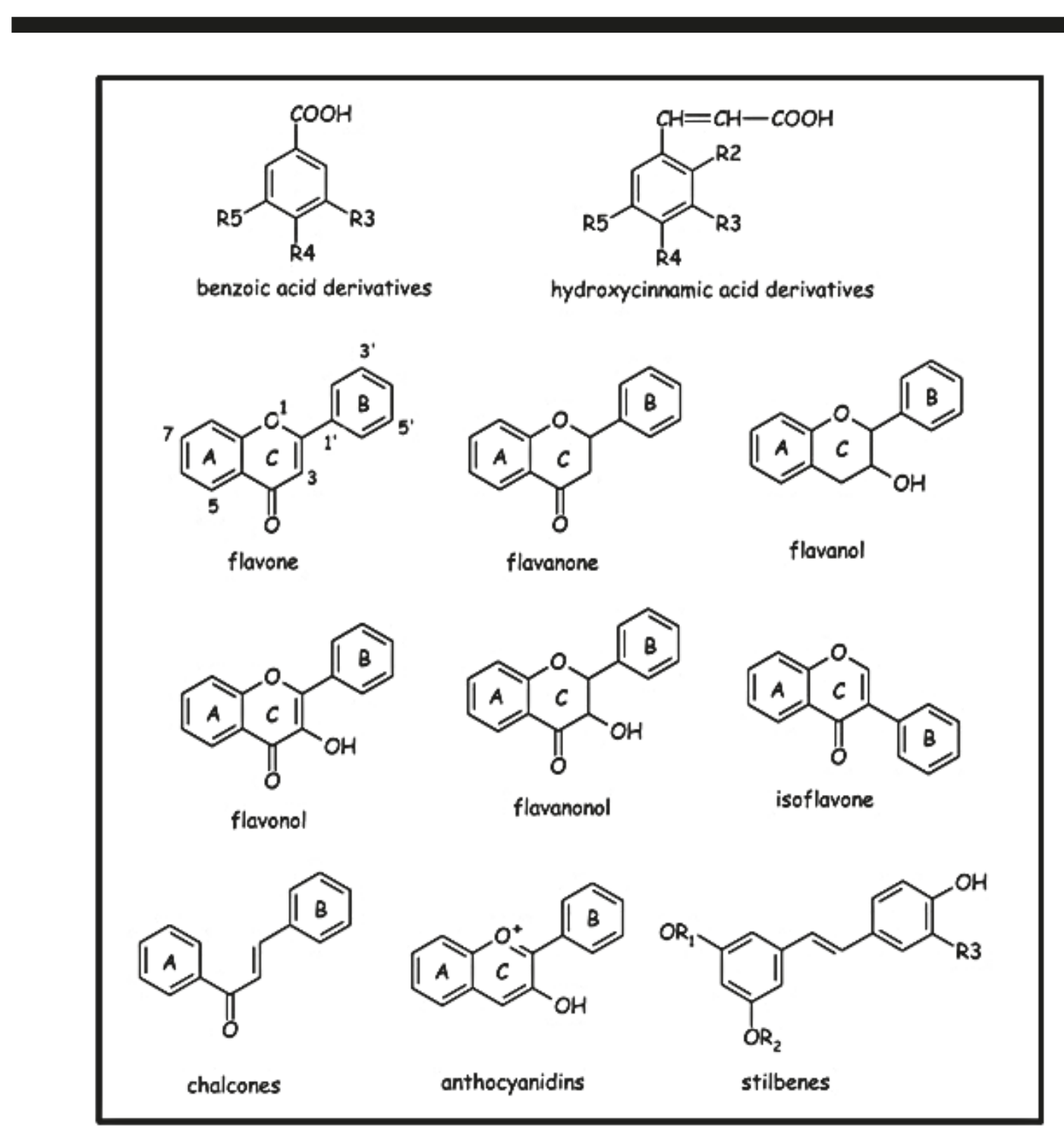

Fig. 7. Estructuras básicas de ácidos benzoicos, flavonoides y estilbenos [11].

La L-fenilalanina es el precursor común de la mayoría de los fenoles de origen vegetal. Estas reacciones requieren de una gran demanda de nitrógeno, dependiendo del compuesto a formarse el requerimiento será mayor o menor.

Son dos las enzimas implicadas en las rutas de formación de los flavonoides, la primera la isoflavona sintetasa y la segunda, la 2-oxoglutarato-dependiente flavona sintetasa.

Carotenoides y xantófilas: Los carotenoides son pigmentos lipofílicos que confieren el color amarillo, naranja o rojo a muchas frutas y verduras. Los carotenoides presentes en los alimentos son 
generalmente tetraterpenos o tetraterpenoides. Estos están agrupados en 8 subunidades de isoprenoides $\mathrm{C}^{5}$ unidas las cabezas con las colas (figura 8).

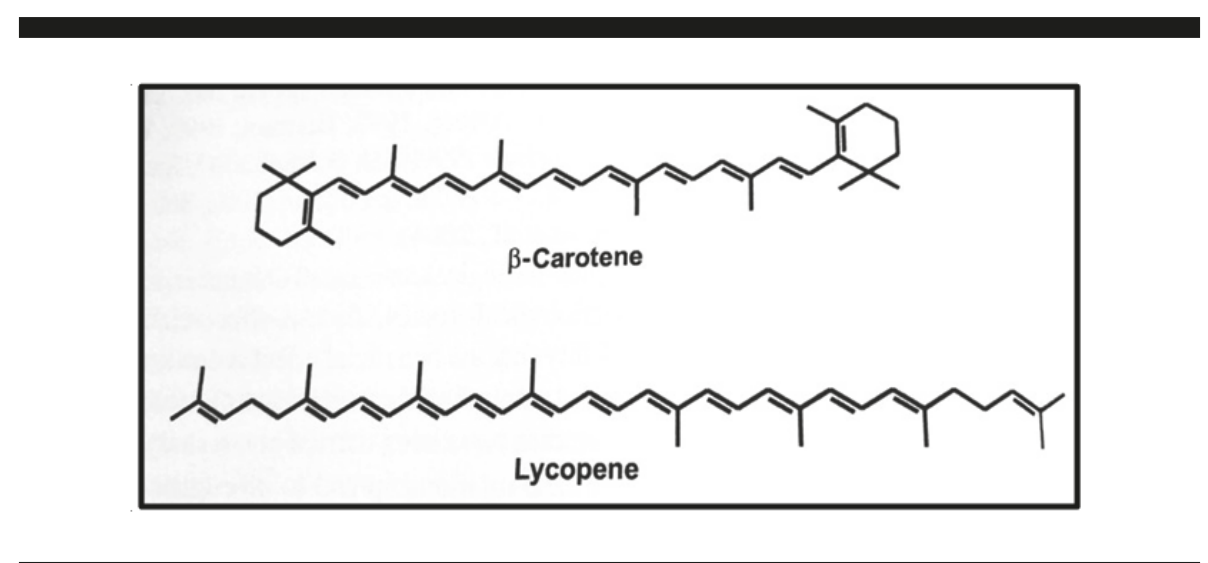

Fig. 8. Estructuras químicas de carotenoides [12].

El esqueleto básico es lineal y simétrico con grupos metilos situados a los lados, y están separados por seis átomos de carbono en el centro y los otros por cinco átomos de carbono. Modificaciones en esta estructura básica como por ejemplo ciclaciones, hidrogenaciones, deshidrogenaciones, migraciones de enlaces dobles, reordenamientos, acortamientos o alargamientos de las cadenas son las responsables de las formaciones de diversas y variadas estructuras.

En la naturaleza, los carotenoides existen principalmente en la estructura estable trans, aunque existen algunos isómeros cis que se han detectado en alimentos. Estas estructuras cis aparecen sobre todo durante procesos térmicos y durante la exposición a la luz. La única excepción es el bixin, el principal pigmento del colorante annatto, el cual por naturaleza tiene estructura cis.

Los carotenoides pueden ser acíclicos (licopeno) o pueden tener un anillo de seis componentes en un extremo ( $\gamma$-caroteno y $\delta$-caroteno) o bien tener anillos en los dos extremos $(\alpha$-caroteno y $\beta$-caroteno). Excepcionalmente los carotenoides que predominan en el pimiento rojo, la capsantina y la capsorrubina, contienen anillos de cinco componentes.

Los hidrocarburos carotenoides reciben el nombre de carotenoides, mientras que las xantofilas son los derivados de éstos hidrocarburos oxigenados. Los oxígenos sustitutivos presentes en las xantofilas son grupos hidroxi, grupos ceto, grupos epoxi y grupos aldehído. Estos grupos determinan el grado de polaridad y la solubilidad de las xantofilas.

Se han encontrado alrededor de 100 carotenoides distintos en los alimentos. Por lo general, un alimento contiene entre 1 y 5 carotenoides que predominan, y otros en una menor proporción que se pueden caracterizar a nivel de trazas [19].

Aminoácidos, péptidos y proteínas: Recientemente ha surgido un gran interés por los péptidos llamados 'bioactivos'. Son unos pequeños fragmentos peptídicos que resultan inactivos cuando se encuentran dentro de la secuencia paternal, pero una vez son separados de la misma por hidrólisis 
enzimática, pueden realizar numerosas funciones. Estos péptidos tienen el tamaño de entre 2 y 20 aminoácidos y no superan pesos moleculares mayores de $6 \mathrm{KDa}$.

Entre las numerosas funciones que realizan, se encuentra la actividad antioxidante, así como función antimicrobiana, antitrombosis y funciones antihipersenstitivas entre otras.

En concreto los péptidos con capacidad antioxidante se componen de entre 5 y 16 aminoácidos residuales. Son considerados como seguros, saludables, de bajo peso molecular, de bajo coste económico, con una alta eficacia y una fácil absorción. Resultan más estables en condiciones adversas que los antioxidantes enzimáticos. Se encuentran en dos formas diferentes: hidrolizados de proteínas precursoras o como péptidos bioactivos [20].

Varios estudios han demostrado la presencia de estos péptidos en material vegetal (Tabla 1), tales como cacahuetes [21], salvado de arroz [22], girasol [23], hoja de alfalfa [24], harina de maíz [25] y hojas de curry [26].

Tabla 1. Péptidos antioxidantes [27]

\begin{tabular}{|c|c|}
\hline Origen del péptido & Actividad \\
\hline $\begin{array}{l}\text { Proteína del endospermo del arroz } \\
\qquad(\text { Oryza sativa })\end{array}$ & $\begin{array}{l}\text { Inhibición de la autooxidación, actividad superóxido } \\
\text { y actividad de eliminación de hidroxilos }\end{array}$ \\
\hline $\begin{array}{l}\text { Proteína de semilla de cacahuete } \\
\quad \text { (Arachis hypogaea) }\end{array}$ & $\begin{array}{l}\text { Inhibición de la oxidación del LDL humano, } \\
\text { y de la actividad de metales quelantes }\end{array}$ \\
\hline $\begin{array}{l}\text { Proteína de girasol } \\
\text { (Helianthus annus) }\end{array}$ & Actividad quelante de cobre \\
\hline $\begin{array}{l}\text { Proteína de hoja de alfalfa } \\
\qquad(\text { Medicago sativa })\end{array}$ & $\begin{array}{l}\text { Reduce el poder oxidativo, quelante de radicales libres } \\
\text { y actividades de eliminación de radicales libres }\end{array}$ \\
\hline $\begin{array}{l}\text { Proteína de maíz hidrolizada } \\
\qquad(\text { Zea mays })\end{array}$ & Quelante de radicales libres y actividades de eliminación de radicales libres \\
\hline $\begin{array}{l}\text { Harina de gluten de maíz } \\
\qquad(\text { Zea mays })\end{array}$ & Reduce el poder oxidativo y eliminación de radicales libres \\
\hline $\begin{array}{l}\text { Proteína de cacahuete } \\
\text { (Arachis hypogaea) }\end{array}$ & $\begin{array}{l}\text { Inhibición de la oxidación del ácido linoleico, reduce el poder oxidativo } \\
\text { e inhibe la oxidación hepática }\end{array}$ \\
\hline $\begin{array}{l}\text { Tubérculos de batata } \\
\text { (Ipomoea batatas) }\end{array}$ & Inhibición de la oxidación del ácido linoleico \\
\hline $\begin{array}{l}\text { Fracciones de proteína de soja } \\
\qquad(\text { Glycine max })\end{array}$ & $\begin{array}{l}\text { Actividad antioxidante en emulsiones, eliminación de radicales libres } \\
\text { y reducción del poder oxidativo }\end{array}$ \\
\hline
\end{tabular}

Estas propiedades antioxidantes están íntimamente relacionadas con la composición, estructura y la hidrofobicidad. Por ejemplo, los aminoácidos tirosina (Tyr), triptófano (Trp), metionina (Met), lisina (Lys), cisteína (Cys) e histidina (His) son los que poseen actividad antioxidante. Esto se debe a que al tener residuos aromáticos pueden donar protones a radicales deficientes en electrones. También es importante tener en cuenta la posición correcta del aminoácido dentro de la secuencia peptídica. Cualquier cambio o modificación en la disposición de aminoácidos en tripéptidos derivará en una actividad antioxidante distinta [27]. 


\section{PRINCIPALES ESPECIES VEGETALES CON ACTIVIDAD ANTIOXIDANTE}

\section{Camellia sinensis}

El té negro y el té verde derivan de esta planta (figura 9a) la diferencia radica en que para el té negro las hojas sufren una fermentación de las hojas mientras que para el té verde se consumen frescas. Varios estudios han comparado la capacidad antioxidante del té con antioxidantes sintéticos como el BHA, BHT y TBHQ, así como con el $\alpha$-tocoferol. En todos los casos, el té resultó ser más efectivo que los antioxidantes sintéticos [3]. El compuesto antioxidante más relevante en el té verde es una catequina, que junto con apicatequinas, epicatequina galato, epigalocatequina y epicalocatecina galato hacen del extracto de té una mezcla de antioxidantes con alta capacidad de quelar iones metálicos y de atrapar radicales libres de oxígeno [3].

Las catequinas son un tipo de compuestos polifenólicos. Se trata de una molécula con tres grupos hidroxilos en el anillo aromático junto con un grupo glucogallin en el anillo del carbono [10].

El té negro contiene otro tipo de compuestos fenólicos, las teaflavinas y las tearubiginas resultan igual de efectivas que las catequinas, aunque en todos los casos el té verde presenta mayor capacidad antioxidante que el negro $[10,28]$.

\section{Rosmarinus officinalis L. y Salvia officinalis L.}

El extracto de romero (Rosmarinus officinalis L.) y el de salvia (Salvia officinalis L.) son muy utilizados como antioxidantes naturales debido a su fuerte capacidad antioxidante y a su propiedad de ser soluble en grasas (figura 9d y 9b respectivamente). En 1995 se publicó por primera vez el uso del extracto de romero como antioxidante, comparándolo con los antioxidantes sintéticos más comunes (BHA y BHT). Son los fenólicos diterpenos los responsables de estas propiedades en ambas especies, concretamente el ácido carnósico (el de mayor concentración), el carnosol, el rosmanol, epi-rosmanol, iso-rosmanol, rosmadial y el carnosato de metilo [29].

El extracto de romero se ha probado en diferentes aceites comestibles, tales como aceite de girasol, de oliva, de colza y de maíz. Los resultados de este estudio sugieren que el polvo de romero es más efectivo en aceites con contenidos altos de ácidos grasos poliinsaturados. El uso de los extractos de romero y de salvia ya están aceptados formalmente en las regulaciones Europeas como un nuevo aditivo alimentario y se asignan con su número E-392 (Comisión Directiva 2010/67/EU y 2010/69/EU).

El método de Rancimat se emplea habitualmente para medir la estabilidad oxidativa del aceite. Este está basado en la medición del periodo de inducción mediante la detección de formación de ácidos volátiles durante la oxidación del aceite. En estudios realizados mediante el análisis Rancimat [29] se demostró que el extracto de romero y el extracto de salvia eran más efectivos en el contexto de estabilidad oxidativa que los antioxidantes sintéticos.

El ácido carnósico es el mayor componente activo en estas dos especies vegetales y también el que presenta mayor capacidad antioxidante. Su estructura quimica se compone de dos grupos hidroxilos O-fenólicos localizados en el anillo aromático, en comparación con el BHA y el BHT que tienen solo un grupo hidroxilo. El número de grupos hidroxilos O-fenólicos determina la capacidad antioxidante de un compuesto. Otros compuestos identificados en el romero y en la salvia han sido el rosmanol, el rosmaridifenol y el ácido rosmarínico [29]. 
La adición del extracto de romero en aceites para freír redujo los productos de oxidación tanto primaria como secundaria [30]. Los dienos y trienos conjugados son compuestos secundarios que se producen a elevadas temperaturas. La adición de extracto de romero al aceite de colza previene la formación de estos compuestos durante la fritura de aceites. A mayor número de ácidos grasos poliinsaturados, mayor es la producción de estos compuestos secundarios. El aceite de oliva es el que presenta menos cantidad de dienos y trienos conjugados en comparación con el aceite de girasol o el de colza [31].

En otros estudios se ha probado el efecto de adición de romero en polvo [31] comparándolo con otras especies vegetales en el mismo formato, y en ellos el romero mostró tener la más alta capacidad antioxidante. El polvo de romero se mezcló con aceite de maíz y la concentración $0,5 \% \mathrm{w} / \mathrm{v}$ resultó ser la más óptima.

\section{Peumus boldus Mol.}

El boldo (figura 9c) tiene gran capacidad antioxidante por la potente habilidad para eliminar radicales libres [32]. Los compuestos mayoritarios presentes en Peumus boldus son los flavonoides, el más conocido es la boldina, aunque también contiene reticulinas, kaempferitrinas y quercetinas. Estudios científicos [33] se han enfocado sobre todo en sus hojas, ya que es la parte vegetativa de la planta que ha mostrado tener las mayores concentraciones de antioxidantes [34].

\section{Sesamum indicum $\mathrm{L}$.}

El aceite de sésamo contiene un antioxidante especial y muy fuerte conocido como sesamol (3,4-metiletileno dyoxifenol), además de otros dos componentes, sesamin y sesamolin, estando este último en la mayor cantidad. En algunos estudios se ha usado como un antioxidante natural en aceite de girasol. Las semillas de sésamo se doran previamente a $180{ }^{\circ} \mathrm{C}$, ya que de esta manera se incrementa la eficacia de los componentes antioxidantes. En otro estudio se observó que el sesamol a concentraciones de 200 ppm tenía mayor efecto que el BHT [35]. El sesamol es un compuesto fenólico especial, ya que es soluble tanto en medios acuosos como en medios oleosos, y además posee estabilidad térmica. Contiene un grupo benzodioxol, conocido por eliminar radicales libres hidroxilos y por producir 1,2- dihidroxibenceno. Todo esto hace al sesamol mucho más interesante en cuanto a capacidad antioxidante que los otros dos compuestos (el sesamin y el sesamolin) [35]. A pesar de que la extracción de sesamol para utilizarlo únicamente como antioxidante no resulta económicamente beneficiosa, es posible conseguirlo, si se aprovechan los subproductos de la producción del aceite de sésamo [4] (figura 9f). 


\section{Ocimum basilicum L.}

La albahaca (figura 9g) es una de las plantas más explotadas para la extracción de sus aceites esenciales y el ácido rosmarínico es el compuesto fenólico más presente en esta planta. Cuando se comparó la actividad de eliminación de radicales libres entre el BHA (antioxidante sintético) y el extracto de albahaca a bajas concentraciones, el BHA presentó mayor eficiencia que el extracto de albahaca, sin embargo, a concentraciones de $100 \mu \mathrm{g} / \mathrm{ml}$ los efectos resultaron los mismos [36].

Se observó que el extracto de albahaca inhibe la oxidación del ácido linoleico, y consecuentemente inhibe la decoloración de los $\beta$-carotenos. Los compuestos fenólicos son capaces de eliminar el radical alquil-peroxisol que se genera por la autooxidación del ácido linoleico. Por otra parte, se indujo con cobre la oxidación del aceite de girasol y se midió en presencia y en ausencia de antioxidantes. Tanto con el extracto de albahaca como con el BHA, los resultados mostraron que la albahaca actuaba como un potente quelante de cobre, propiedad común de los polifenoles naturales.

\section{Olea europaea}

El olivo es una especie vegetal en la que todavía no se ha estudiado en detalle sus propiedades antioxidantes, no obstante, la demanda de extracto de hoja de olivo (figura 9e) ha incrementado recientemente para utilizarlo como aditivo alimentario o para desarrollar alimentos funcionales [17]. Existen cinco grupos de compuestos fenólicos presentes en las hojas del olivo: oleuropeosidos, catequinas, flavonas, flavonoles y fenoles sustituidos. Estos grupos de fenoles derivan en compuestos como el hidroxitirosol, tirosol, ácido cafeico, ácido p-cumárico, ácido vanílico, vanilina, oleuropeina, luteolina, diosmetina, rutina, etc. En concreto la oleuropeína es el compuesto en mayor grado o proporción y se asocia con una actividad antioxidante $[37,38]$.

\section{Glycyrrhiza glabra}

La regaliz es una planta que ha sido utilizada desde hace cientos de años como condimento culinario o como planta medicinal (figura 9i). Se trata de una planta herbácea perenne, nativa de la región Mediterránea, Rusia central y Asia menor.

Las saponinas triterpenoides y los flavonoides son los principales compuestos fenólicos presentes en la regaliz. Los compuestos fenólicos son los responsables de los efectos biológicos y farmacológicos de esta especie, incluyendo la actividad antioxidante, estos compuestos son: las liquiritigeninas, las glabrenas, las glabridinas, los glabroles, las isoliquiritinas, las liquiritinas apiósidas, las isoliquiritinas apiósidas y los glicósidos de regaliz. En Estados Unidos esta especie es considerada como un aditivo alimentario seguro y es preparado generalmente a partir de la raíz [41].

\section{Zingiber officinale Rosc.}

La composición del extracto de jengibre (figura 9h) está basada en sesquiterpenos, carbonilos, alcoholes e hidrocarburos monoterpenos. Los compuestos picantes no volátiles presentes como gingeroles, shogaoles, paradoles y la zingerona presentan actividad antioxidante por eliminación de radicales libres. En diferentes estudios [39,40] se compararon los efectos antioxidantes del jengibre con el antioxidante sintético BHT. La capacidad antioxidante del jengibre resulta ser muy superior a la del BHT. En una publicación reciente se ha demostrado que la adición de extracto de jengibre a 
aceites comerciales, como el aceite de colza, permitiría mantener el contenido de ácidos grasos en su máxima concentración posible, a diferentes temperaturas [41].

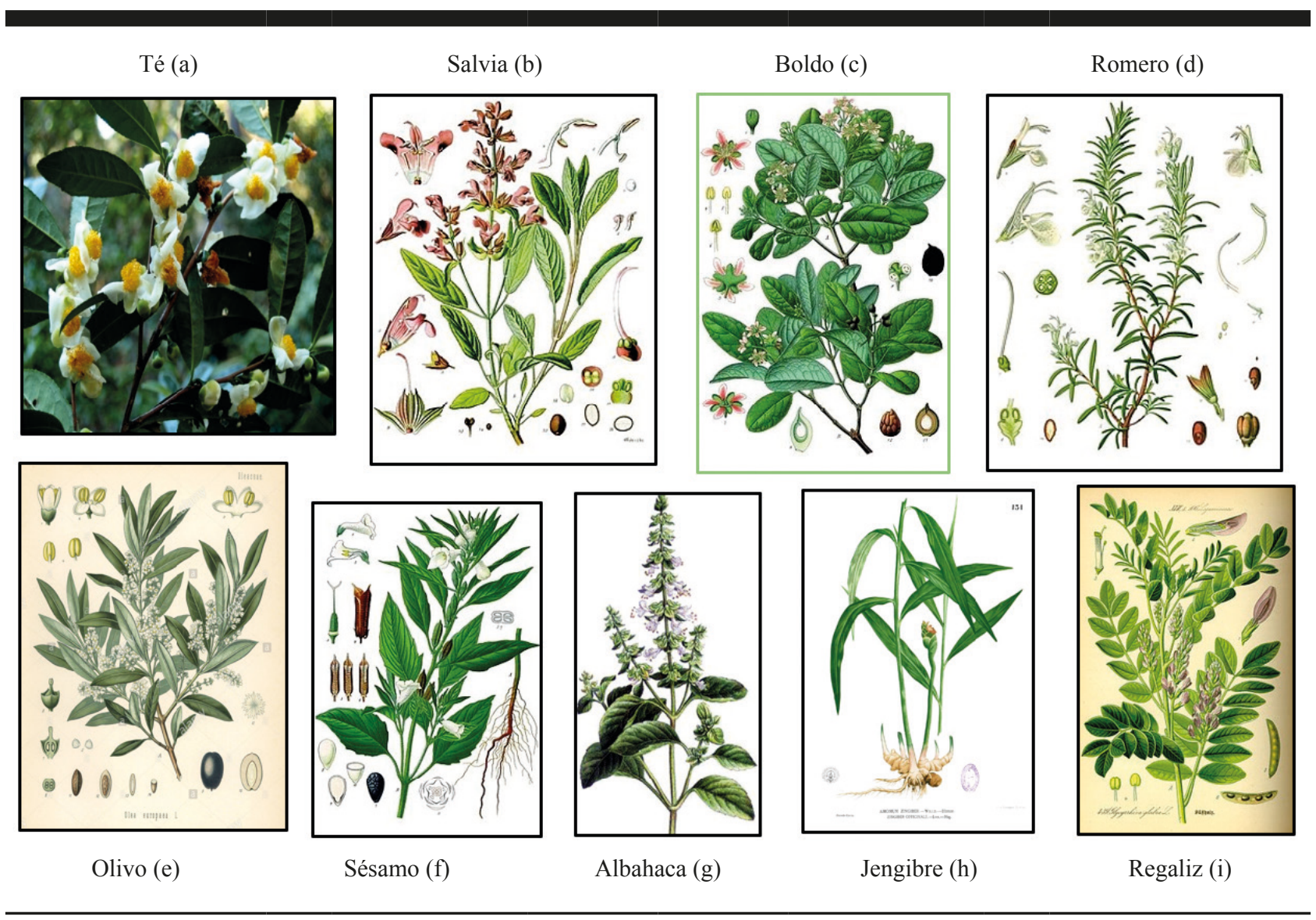

Fig. 9. Imágenes y nombres communes de las principales especies vegetales con actividad antioxidante [42].

A continuación se muestran distintas tablas que recogen especies vegetales que poseen capacidad antioxidante, aunque todavía no están muy estudiadas por la comunidad científica.

Tabla 2. Especies aromáticas con compuestos antioxidantes

\begin{tabular}{ccc}
\hline Especie vegetal & Compuestos antioxidantes & Referencia bibliográfica \\
\hline Cúrcuma & Curcuminoides & Schieffer (2002) \\
$($ Curcuma longa $)$ & Fenoles: ácidos & Chun, Vattem, Lin \\
Orégano & cafeico y rosmarínico & \& Shetty (2004) \\
(Origanum vulgare $)$ & Flavonoides y & Chatterje, Varijar \& \\
Fenogreco & quercetinas glicosiladas & Sharma (2009) \\
\hline
\end{tabular}


Tabla 3. Especies hortícolas con compuestos antioxidantes

\begin{tabular}{|c|c|c|}
\hline Especie vegetal & Compuestos antioxidantes & Referencia bibliográfica \\
\hline Brassica spp. & $\begin{array}{c}\text { Flavonoides y derivados del } \\
\text { hidroxicinanimol }\end{array}$ & $\begin{array}{c}\text { Price, Casuscelli, } \\
\text { Colquoun \& Rhodes (1998) }\end{array}$ \\
\hline $\begin{array}{l}\text { Melón amargo } \\
\text { (momordica charantia) }\end{array}$ & $\begin{array}{l}\text { Fenoles: catequina, } \\
\text { epicatequina y ácidos gálico, gentísico y clorogénico }\end{array}$ & Horax, Hettiarachchy \& Chen (2010) \\
\hline $\begin{array}{c}\text { Zanahoria } \\
\text { (daucus carota) }\end{array}$ & $\begin{array}{l}\text { Fenoles: ácidos clorogénico, } \\
\text { cafeico, ferúlico y cinámico }\end{array}$ & Sharma, Karki, Thakur \& Attri (2012) \\
\hline $\begin{array}{c}\text { Cebolla } \\
\text { (allium cepa) }\end{array}$ & $\begin{array}{l}\text { Flavonoides: quercetina, } \\
\text { kaemferol, miricetina y catequina }\end{array}$ & $\begin{array}{c}\text { Pérez-Gregorio, Regueiro, Simal- Gándara, } \\
\text { Rodrigues \& Almeida (2014) }\end{array}$ \\
\hline $\begin{array}{c}\text { Patata } \\
\text { (solanum tuberosum) }\end{array}$ & $\begin{array}{l}\text { Fenoles: ácidos clorogénico, } \\
\text { gálico, cafeico y quercetina }\end{array}$ & Friedman (1997) \\
\hline $\begin{array}{c}\text { Batata } \\
\text { (ipomoea batatas) }\end{array}$ & $\begin{array}{l}\text { Fenoles: ácidos clorogénico, } \\
\text { isoclorogénico y cinámico, cianidina y peonidina }\end{array}$ & Oki et al. (2002) \\
\hline $\begin{array}{l}\text { Remolacha } \\
\text { (beta vulgaris) }\end{array}$ & $\begin{array}{l}\text { Betalaína, betacianina, } \\
\text { betanidina,isobetanidina, isobetanina, amarantina. }\end{array}$ & $\begin{array}{c}\text { Kujala, Loponen, } \\
\text { Klika \& Pihlaja (2000) }\end{array}$ \\
\hline $\begin{array}{c}\text { Espárrago } \\
\text { (asparagus officinalis) }\end{array}$ & Rutina & Rodriguez et al.(2005) \\
\hline $\begin{array}{l}\text { Lechuga } \\
\text { (lactuca sativa) }\end{array}$ & $\begin{array}{l}\text { Flavonoides: quercetina y } \\
\text { luteolina }\end{array}$ & $\begin{array}{l}\text { Llorach, Martínez-Sánchez, Tomás- Bar- } \\
\text { berán, Gil \& Ferreres (2008) }\end{array}$ \\
\hline $\begin{array}{c}\text { Espinaca } \\
\text { (spinacea oleracea) }\end{array}$ & Flavonoides & Aritomi \& Kawasaki (1984) \\
\hline
\end{tabular}

Tabla 4. Especies frutales con compuestos antioxidantes

\begin{tabular}{|c|c|c|}
\hline Especie vegetal & Compuestos antioxidantes & Referencia bibliográfica \\
\hline $\begin{array}{c}\text { Mora } \\
\text { (morus spp.) }\end{array}$ & $\begin{array}{c}\text { Antocianinas: cianidina-3- } \\
\text { glucósida, cianidina 3-rutinoside. Fenólicos: ácidos } \\
\text { gálico, cafeico, } \\
\text { ferúlico, p-cumárico y elágico }\end{array}$ & Pereira (2004) \\
\hline $\begin{array}{l}\text { Grosella negra } \\
\text { (ribes nigrum) }\end{array}$ & Fenoles y proantocianinas & Shahidi \& Naczk (2004) \\
\hline $\begin{array}{c}\text { Frambuesa } \\
\text { (rubus idaeus L.) }\end{array}$ & $\begin{array}{c}\text { Taninos hidrosolubles y } \\
\text { antocianinas }\end{array}$ & $\begin{array}{c}\text { Kafkas, Özguen, } \\
\text { Ögozul \& Turemis (2008) }\end{array}$ \\
\hline $\begin{array}{c}\text { Uva } \\
\text { (vitis vinifera) }\end{array}$ & $\begin{array}{l}\text { Flavonoides: catequinas, } \\
\text { quercetinas y antocianinas No flavonoides: ácido } \\
\text { gálico y resveratrol }\end{array}$ & Yang, Martinson Liu (2009) \\
\hline Cerasus spp. & Fenoles: kaemferol, quercetina & Gao \& Mazza (1995) \\
\hline $\begin{array}{c}\text { Manzana } \\
\text { (malus domestica) }\end{array}$ & $\begin{array}{l}\text { Fenoles: ácidos hidroxicinámicos, } \\
\text { flavan-3-oles, antocianidinas, flavonoles y dihidrox- } \\
\text { ichalconas }\end{array}$ & Wolfe, Wu \& Liu (2003) \\
\hline $\begin{array}{c}\text { Cítricos } \\
\text { (citrus spp.) }\end{array}$ & Flavonoides y cumarinas & Naczk \& Shahidi (2006) \\
\hline $\begin{array}{c}\text { Pomelo } \\
\text { (citrus } x \text { paradisi) }\end{array}$ & $\begin{array}{c}\text { Taninos hidrosolubles y } \\
\text { antocianinas }\end{array}$ & Abbas (2014) \\
\hline
\end{tabular}


Un diverso rango de compuestos antioxidantes endógenos se encuentran en las especies vegetales. Numerosas publicaciones relatan la evidencia creciente de que el consumo de una variedad de compuestos antioxidantes presentes en alimentos naturales de origen vegetal puede disminuir el riesgo de serios desórdenes en la salud humana debido a sus actividades antioxidantes, además de otros mecanismos. También hay un interés creciente en la adición exógena de estos compuestos como enriquecimiento de alimentos con el objetivo de disminuir el uso de antioxidantes sintéticos, ya que los consumidores han expresado un deseo de una preferencia de alternativas naturales. La adición de estos extractos no causan cambios significativos en las características organolépticas o en el valor nutricional del alimento.

Hay una relación inversa entre la cantidad de antioxidantes ingeridos en la dieta y la incidencia de enfermedades humanas. El modo de actuación de estos compuestos fenólicos en el organismo humano deberá ser estudiado más en profundidad. Debido a cuestiones de seguridad y a otras cuestiones que conciernen a los antioxidantes sintéticos, los antioxidantes naturales obtenidos de fuentes naturales y comestibles resultan una alternativa lógica. Existen numerosos compuestos naturales que pueden ser extraídos con bajo coste, aprovechando los residuos de otros procesos de la industria alimentaria o agronómica.

Futuros estudios deberán basarse en el aislamiento de estos compuestos antioxidantes y la observación de sus efectos en animales de experimentación y posteriormente en humanos, con el objetivo de evaluar sus beneficios.

\section{REFERENCIAS BIBLIOGRÁFICAS}

[1] Redondo-Cuevas L, Castellano G, Raikos V. Natural antioxidants from herbs and spices improve the oxidative stability and frying performance of vegetable oils. 2018. International Journal of Food Science and Technology. 2017;52(11):2422-8. DOI: 10.1111/ijfs.135264.

[2] Lobo V, Patil A, Phatak A, Chandra N. Free radicals, antioxidants and functional foods: Impact on human health. Pharmacognosy Reviews. 2010;4(8):118-26. DOI: 10.4103/0973-7847.70902.

[3] Reiter R, Tan D, Galano A. Melatonin reduces lipid peroxidation and membrane viscosity. 2019. Frontiers in physiology. 2014;5(377):1-4. DOI: 10.3389/fphys.2014.00377.

[4] Taghvaei, M, Jafari SM. Application and stability of natural antioxidants in edible oils in order to substitute synthetic additives. Association of Food Scientists \& Technologists. 2015;52:127282.

[5] Shahidi F, Ambigaipalan P. Phenolics and polyphenolics in foods, beverages and spices: Antioxidant activity and health effects-A review. Journal of Functional Foods. 2015;18:820-97.

[6] Choe E, Min DB. Mechanisms of Antioxidants in the Oxidation of Foods. 2019. Comprehensive Reviews in Food Science and Food Safety. 2009;8(4):345-58. DOI: 10.1111/j.15414337.2009.00085.x.

[7] Johnson DR, Decker EA. The Role of Oxygen in Lipid Oxidation Reactions: A review. Annual Reviews of food Science and Technology. 2015;6:171-90.

[8] Kristinova V, Mozuraityte R, Aaneby J, Storrø I, Rustad T. Iron-mediated peroxidation in marine emulsions and liposomes studied by dissolved oxygen consumption. Eur. J. Lipid Sci. Tech. 2014;116:207-25. 
[9] Kamal-Eldin A., Appelqvist LA. The chemistry and antioxidant properties of tocopherols and tocotrienols. Lipids. 1996;31:671-701.

[10] Pardau MD, Pereira AS, Apostolides Z, Serem JC, Bester MJ. Antioxidant and anti-inflammatory properties of Ilex guayusa tea preparations: a comparison to Camellia sinensis teas. 2019. Food \& Function. 2017;8:4601-4610. DOI: 10.1039/c7fo01067b.

[11] Leopoldini M, Russo N, Toscano M. The molecular basis of working mechanism of natural polyphenolic antioxidants. Food Chemistry. 2011;125:288-306.

[12] Shahidi F. Handbook of Antioxidants for Food Preservation, first ed., Woodhead Publishing Series in Food Science. Cambridge, UK: Elsevier; 2015.

[13] Taghvaei M, Jafari SM. Application and stability of natural antioxidants in edible oils in order to substitute synthetic aditives. Association of Food Scientists \& Technologists. 2015;52:1272-82.

[14] Chotimarkorn C, Benjakul S, Silalai N. Antioxidant components and properties of five longgrained rice bran extracts from commercial available cultivars in Thailand. Food Chemistry. 2008;111:636-41.

[15] Choi Y, Lee J. Antioxidant and antiproliferative properties of a tocotrienol-rich fraction from grape seeds. Food Chemistry. 2009;114:1386-90.

[16] Makinen, M., Kamal-Eldin, A., Lampi, A. M., Hopia, A. Effects of a- and $\gamma$-tocopherol on formation of hydroperoxides and two decomposition products from methyl linoleate. Journal of the American Oil Chemist's Society, 2000;77:801-6.

[17] Choe, E. Chapter 17: Effects and mechanisms of minor compounds in oil on lipid oxidation. In CC Akoh, DB Min (Eds.), Food Lipids. Boca Raton, Florida, USA: CRC Press; 2008:449-74.

[18] Reis FS, Ferreira ICFR, Barros L, Martins A. A comparative study of tocopherols composition and antioxidant properties of in vivo and in vitro ectomycorrhizal fungi. LWT-Food Science and Technology. 2011;44:820-4.

[19] Rodríguez-Amaya DB. Changes in carotenoids during processing and storage of foods. Archivos Latinoamericanos de Nutrición, 1999;49:38S-47S.

[20] Sarmadi BH, Ismail A. Antioxidative peptides from food proteins: a review. Peptides. 2010;31:1949-56.

[21] Hwang JY, Shyu YS, Wang YT, Hsu CK. Antioxidative properties of protein hydrolysate from defatted peanut kernels treated with esperase. Food Sci Technol. 2010;43:285-90.

[22] Revilla E, Maria CS, Miramontes E, Bautista J, García-Martínez A, Cremades O, et al. Nutraceutical composition, antioxidant activity and hypocholes-terolemic effect of a water-soluble enzymatic extract from rice bran. Food Res Int. 2009;42:387-93.

[23] Megías C, Pedroche J, Yust MM, Girón-Calle J, Alaiz M, Millán F., et al. Production of copper-chelating peptides after hydrolysis of sunflower proteins with pepsin and pancreatin. Food Sci Technol. 2008;41:1973-7.

[24] Xie Z, Huang J, Xu X, Jin Z. Antioxidant activity of peptides isolated from alfalfa leaf protein hydrolysate. Food Chem. 2008;111:370-6.

[25] Li XX, Han LJ, Chen LJ. In vitro antioxidant activity of protein hydrolysates prepared from corn gluten meal. J Sci Food Agric. 2008;88:1660-6.

[26] Ningappa M, Srinivas L. Purification and characterization of $35 \mathrm{kDa}$ antioxidant protein from curry leaves (Murraya koenigii L.). Toxicol In Vitro. 2008;22:699-709. 
[27] Sarmadi BH, Ismail A. Antioxidative peptides from food proteins: a review. Peptides. 2010;31:1949-56.

[28] Vermerris W, Nicholson R. Phenolic compound biochemistry. first ed. Springer Netherlands. 2006. DOI: 10.1007/978-1-4020-5164-7.

[29] Yang Y, Song X, Sui X, Qi B, Wang Z, Li Y, Jiang L. Rosemary extract can be used as a synthetic antioxidant to improve vegetable oil oxidative stability. Industrial Crops and Products. 2016;80:141-7.

[30] Alizadeh L, Nayebzadeh K, Mohammadi A. A comparative study on the in vitro antioxidant activity of tocopherol and extracts from rosemary and Ferulago angulata on oil oxidation during deep frying of potato slices. Journal of Food Science and Technology. 2016;53:611-20.

[31] Redondo-Cuevas L. Improving the oxidative stability of oils and fats with natural products. Tesis doctoral UCV; 2018.

[32] Srivastava A, Tandon P, Ayala AP, Jain S. Solid state characterization of an antioxidant alkaloid boldine using vibrational spectroscopy and quantum chemical calculations. Vib. Spectrosc. 2011;56:82-8.

[33] Falé PL, et al. Acetylcholinesterase inhibition, antioxidant activity and toxicity of Peumus boldus water extracts on HeLa and Caco-2 cell lines. Food and Chemical Toxicology. 2012;50(8):26562662. DOI:10.1016/j.fct.2012.04.049.

[34] Velásquez P, Sandoval MI, Giordano A, Gómez M, Montenegro G. Nutricional Composition and Polyphenolic Content of Edible Peumus boldus Mol. Fruits. Ciencia e Investigación Agraria. 2017;44:64-74.

[35] Kumar CM, Singh SA. Bioactive lignans from sesame (Sesamum indicum L.): evaluation of their antioxidant and antibacterial effects for food applications. Journal of Food Science and Technologists. 2015;52:2934-2941. DOI:10.1007/s13197-014-1334-6.

[36] Khatib S, Harnafi M, Touiss I, Bekkouch O, Amrani S, Harnafi H. Phenolic Extract of Basil Prevents Lipid Oxidation in Sunflower Oil, Beef and Turkey Meat: A Comparison with Synthetic Antioxidant BHA. American Journal of Food Science and Nutrition. 2018;5:66-75.

[37] Lee O, Lee B. Antioxidant and antimicrobial activities of individual and combined phenolics in Olea europaea leaf extract. Bioresource Technology. 2010;101:3751-4.

[38] Özcan MM, Matthaus B. A review: benefit and bioactive properties of olive (Olea europaea L.) leaves. European Food Research and Technology. 2017;243:89-99.

[39] Stoilova I, Krastanov A, Stoyanova A, Denev P, Gargova S. Antioxidant activity of a ginger extract (Zingiber officinale). Food Chemistry. 2007;102:764-70.

[40] Singh R, Lawrence R, Lawrence K, Agarwal B, Gupta RK, et al. Antioxidant and Antibacterial Activity of Syzygium aromaticum, Zingiber officinale and Cinnamomum zeylanicum Essential Oils. Chemical Science Transactions. 2015;4:239-45.

[41] Si W, Chen YP, Zhang J, Chen Z, Chung HY. Antioxidant activities of ginger extract and its constituents toward lipids. Food Chemistry. 2018;239:1117-25.

[42] Kolerh, F. E. Medizinal-Pflanzen in naturgetreuen Abbildungen mit kurz erläuterndem texte. Germany: Gera-Untermhaus. Leipzig, 1887. 